\title{
Peripheral giant cell granuloma - case report
}

\author{
Slavoljub Tomić ${ }^{1}$, Bojana Davidović ${ }^{2}$ \\ 'University of East Sarajevo, School of Medicine, Department of Oral Surgery, Foča, Bosnia and Herzegovina; \\ ${ }^{2}$ University of East Sarajevo, School of Medicine, Department of Pediatric and Preventive Dentistry, Foča, Bosnia and \\ Herzegovina
}

\begin{abstract}
SUMMARY
Peripheral giant cell granuloma (PGCG) or "Epulis gigantocelularis" is the most common oral lesion that originates from giant cells. It typically manifests in the form of soft tissue tumor purple-red or red-watery color consisting of multinuclear giant cells in the mononuclear stroma and extravascular erythrocytes. This lesion is not considered true neoplasm, rather reactive lesion stimulated by local irritation and trauma. However, the cause is not known with certainty. This paper presents a 13-year-old boy with a large lesion in the region of right maxillary canine that was retained in jaw despite favorable vertical position and available space to accommodate in the dental arch. The lesion was completely removed under local anesthesia and histopathological findings confirmed the diagnosis of PGCG. Postoperative period went without complications. After four months additional surgical procedure was needed due to the recurrence, which after tooth naturally erupted and positioned in the dental arch.

Keywords: Peripheral giant cell granuloma; Epulis gigantocelularis
\end{abstract}

\section{INTRODUCTION}

Epulis name originates from the Greek epi - on and Oulon - gums, and, in general, considers any growth on gingiva regardless of etiology [1]. Clinically, most epulis lesions look similar and it is difficult to differentiate these from other tumor-like masses. Since large number of gingival lesions macroscopically looks similar to epulis, the literature has not yet determined the official classification of such lesions.

The most common epulis located on gingiva is made up of connective tissue and covered with stratified squamous epithelium - epulus gigantocellularis. It can be found in the literature under different names such as: peripheral giant cell tumor or peripheral giant cell granuloma. It is most commonly found in the intercanine sector on interdental papilla [2], more often on buccal side in the lower jaw [3]. It is five times more common than central giant cell granuloma that develops in bone [4].

Peripheral giant cell granuloma (PGCG) is of unknown etiology and has slow growth [2]. According to most authors, the cause may be permanent irritation or trauma [5]. In some patients diagnosed with PGCG cytomegalovirus has been isolated [6]. However, it has not been confirmed whether it is the cause or just contributes to the development of the disease.

Initially, mucosa shows unchanged color and looks thickened but PGCG eventually grows to an impressive mass, red or dark red in color and soft consistency that can destroy bone [2]. Also, ulcerations may be present on the surface. PGCG usually does not exceed the size of 5 $\mathrm{cm}$ in diameter, but can be bigger. Due to its volume it can push away adjacent teeth [4]. Its base is narrower than its entire volume and impressions of adjacent structures of the oral cavity (teeth, cheeks, language) can be seen on its surface.

It the early stage of its development $\mathrm{x}$-ray does not show any change however after some time changes become noticeable. At this point differential diagnosis should include the central giant cell granuloma.

Treatment is surgical and sometimes requires removing the tooth from the affected area. Recurrent lesions are quite common but they are usually interpreted as the result of inadequate surgery.

The aim of this case report was to present PGCG in 13-year-old boy that was removed by simple surgical procedure that enabled normal eruption of canine and its placement in the dental arch.

\section{CASE REPORT}

A 13 -year-old boy presented at the Clinic for Oral Surgery, Faculty of Medicine Foca, with evident tumefaction on the alveolar ridge of maxilla in the region of the right canine. Lesion was $3.5 \times 2.5 \mathrm{~cm}$ in size, kidney-shaped, redpurple in color and localized in the space of mesial surface of the first right premolar up to the mid part of upper right central incisor, both on vestibular and palatal sides, fulfilling almost the entire vestibule (Figures 1 and 2). X ray revealed right canine present in the bone that could not erupt due to this lesion on ginigiva (Figure 3). The patient underwent fine aspiration biopsy, which after histopathologic examination confirmed the presence of mul- 


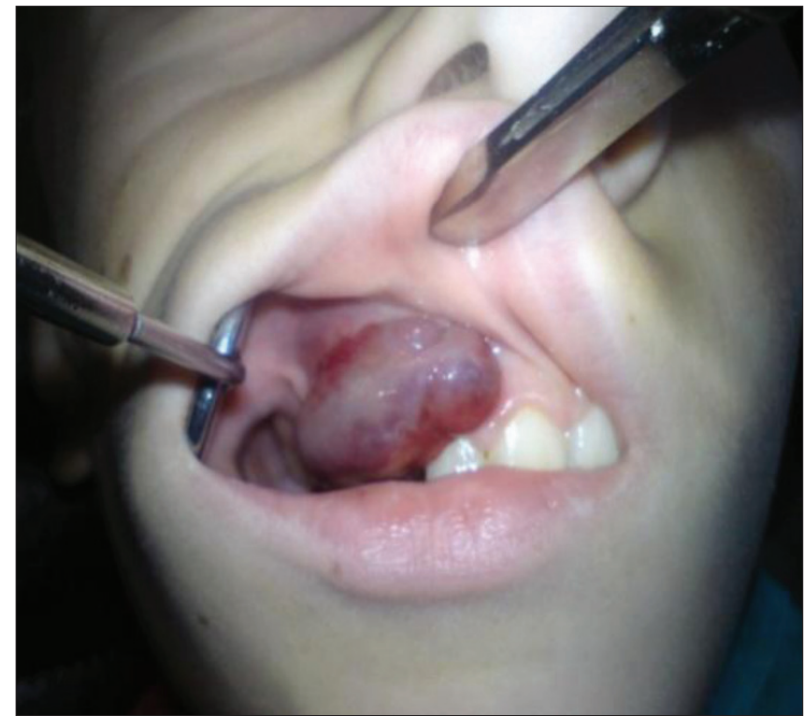

Figure 1. Epulis gigantocellularis - buccal view

Slika 1. Epulis gigantocellularis - izgled sa vestibularne strane

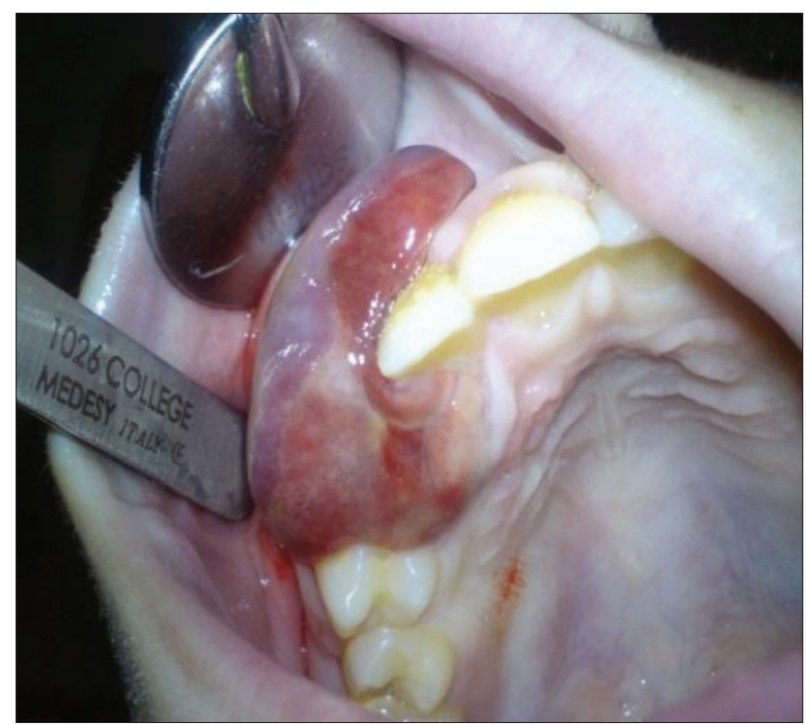

Figure 2. Epulis gigantocellularis- occlusal view

Slika 2. Epulis gigantocellularis - izgled sa okluzalne strane

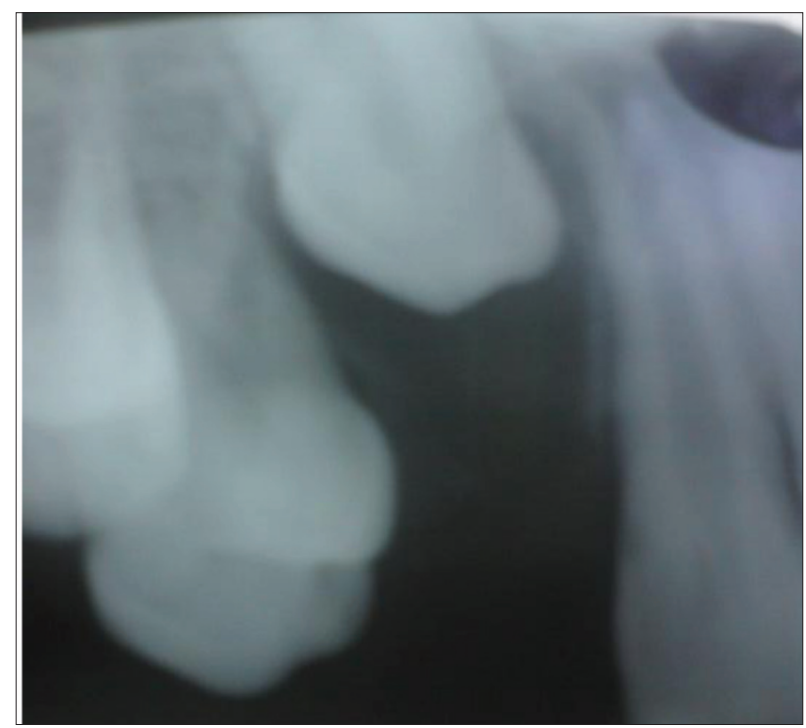

Figure 3. X-ray of unerupted upper right canine Slika 3. Rtg snimak neizniklog desnog gornjeg očnjaka

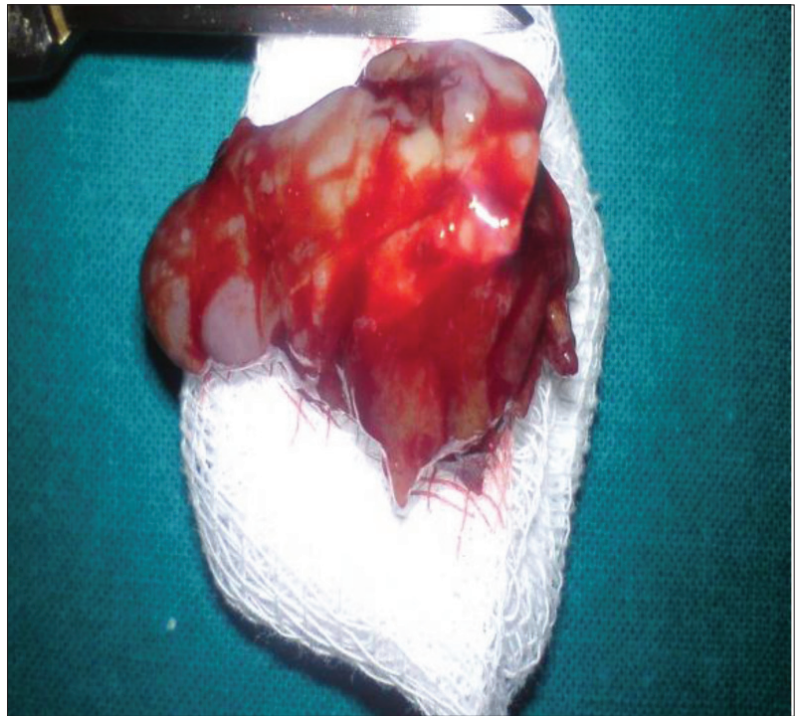

Figure 4. Epulis gigantocellularis completely removed Slika 4. Epulis gigantocellularis uklonjen u potpunosti

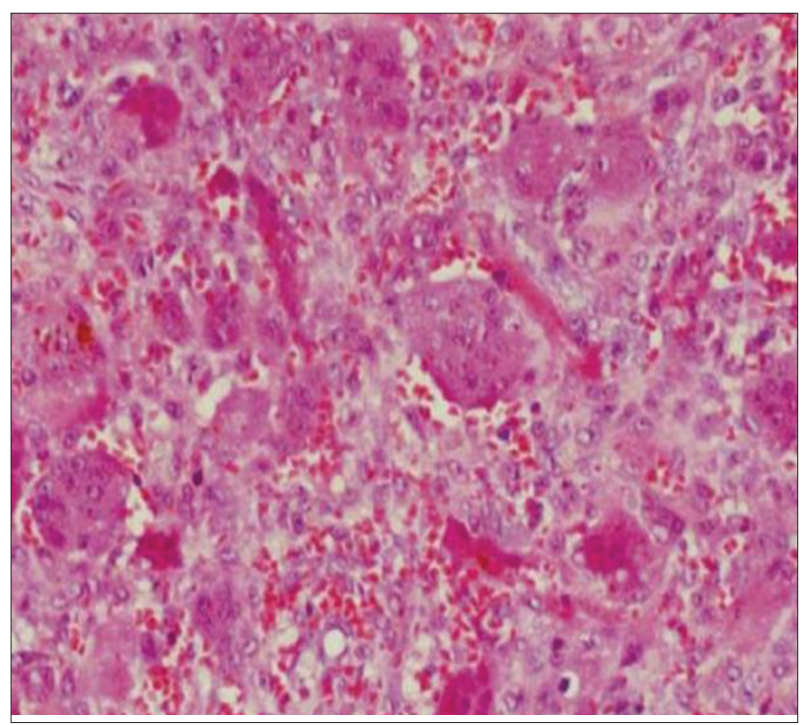

Figure 5. Histopathological finding of epulis gigantocellularis Slika 5. Histopatološki nalaz epulis gigantocellularisa

tinucleate giant cells with hemorrhage around. Spindle / inflammatory cells were not detected.

Surgical removal of the lesion was performed under local anesthesia when it was completely removed in one piece and sent for histopathological analysis (Figure 4). Histopathology revealed the presence of numerous multinuclear cells of different shapes and sizes, containing 8-15 nuclei in fibroblast stroma. Expanded endothelial cells with extravasal erythrocytes were also detected. Moreover, the presence of several giant cells within the vascular space, as well as signs of ossification within the stroma was observed (Figure 5). Based on found histopathological changes it was evident that it is a peripheral giant cell lesion. After surgical procedure was done packaged bandage was placed in the defect, which was removed seven days after the procedure.

After four months, the patient came back with the reccurence of the lesion in the form of blue-purple nodule $5 \mathrm{~mm}$ in size (Figure 6), which was again completely re- 


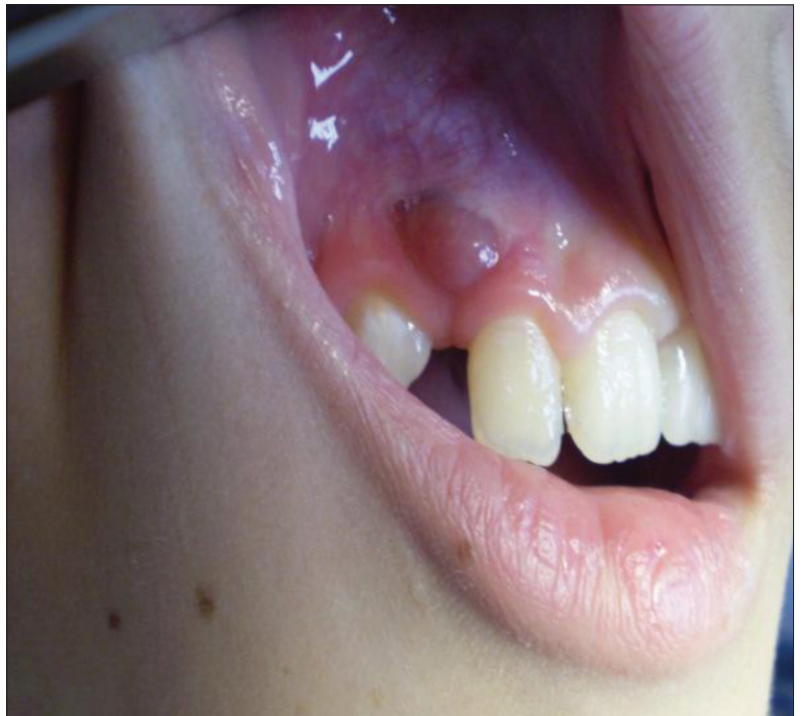

Figure 6. Recurrence of the lesion in the area where it was removed previously

Slika 6. Recidiv na mestu uklonjenog epulis gigantocellularisa

moved under local anesthesia (Figure 7). Canine finally erupted into its space. One year after the intervention, there was no sign of possible recurrence while soft-tissue structures around the teeth fully healed.

\section{DISCUSSION}

Etiology and nature of PGCG remains undefined. In the past there have been several proposed hypotheses that tried to explain the nature of multinuclear giant cells. These include the hypothesis that they are remnants of osteoclasts that perform natural resorption of primary dentition or that have arisen in response to violations of the periosteum.

PGCG can occur any time in life, but the most common incidence is in the mixed dentition [4]. The lesions are more common in the lower jaw $[3,7]$ while its size can reach over $2 \mathrm{~cm}$ in diameter. Clinically it is similar to pyogenic granuloma, but PGCG typically have bluepurple color compared to red pyogenic granuloma. Recently, there was published case of PGCG associated with dental implants [8]. Although PGCG develops in the soft tissue, local bone resorption of the alveolar ridge can be observed as well. Sometimes it is difficult to assess whether the tumor mass is peripheral lesion or central giant cell granuloma (CGCG) that originate in bone tissue of the alveolar ridge and spreads into gingiva $[9,10,11]$.

Histologically, PGCG consists of islands of multinuclear giant cells in the stroma filled with oval and spindle mesenchymal cells and extravasal erythrocytes. Giant cells can contain several to several tens of nuclei. Some of them are large vesicular nuclei, while others are small, pyknotic nuclei. The origin of giant cells is unknown. Ultrastructural and immunological studies [12-16] have shown that they, in fact, originate from osteoclasts [17]. Some researchers believe that they represent reactive component of the lesion, in fact, mononuclear cells from bone marrow that

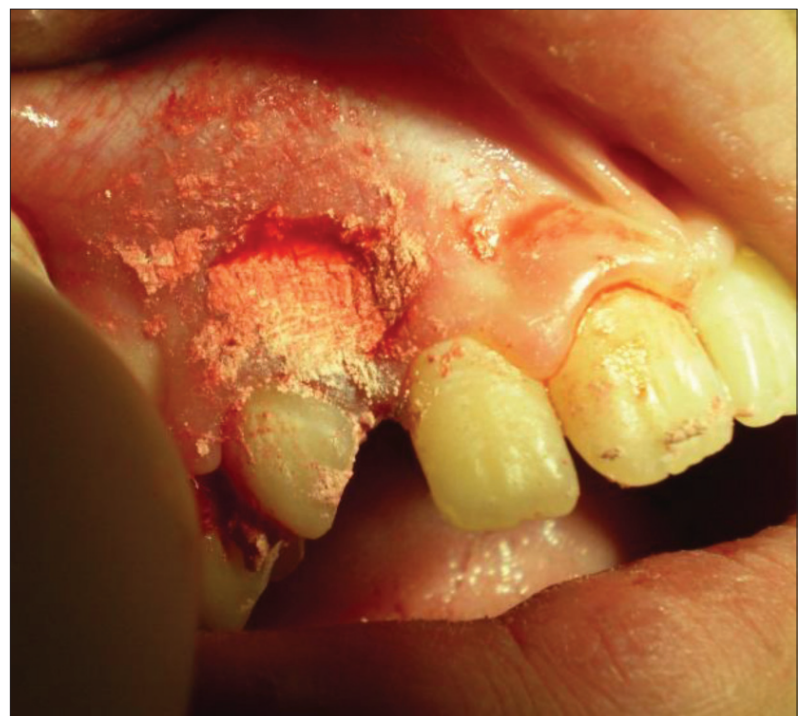

Figure 7. Recurrent lesion removed and retained tooth spontaneously erupted into the dental arch

Slika 7. Uklonjen recidiv i retinirani zub spontano spušten u zubni luk

mature through the bloodstream and their sequential extravasation in response to an unknown stimulus from the stroma. This concept is based on the results of recent studies using cell culture and transplantation $[18,19]$, where giant cells with short life were found and disappeared in culture, in comparison with active proliferation of stromal cells.

According to the findings of Willing et al. [20] it was revealed that stromal cells secrete cytokines and other factors of cell differentiation, including monocyte chemo attractant protein-1 (MCP1), osteoclasts differentiating factor (ODF), and macrophage- stimulating factor (M-CSF). MCP1 is essential for osteoclast differentiation, indicating that stromal cells stimulate migration of monocytes into the tumor tissue fusing in multinucleated giant cells that resemble osteoclasts.

\section{REFERENCES}

1. Beloica D, Vulović MD, Gajić M, et al. Dečja stomatologija. Beograd: Drasler partner, 2005.

2. Rodrigues SV, Mitra DK, Pawar SD, Vijayakar HN. Peripheral giant cell granuloma: This enormity is a rarity. J Indian Soc Periodontol. 2015; 19(4):466-9. [DOI: 10.4103/0972-124X.152411] [PMID: 26392701]

3. Katsikeris N, Kakarantza-Angelopoulou E, Angelopoulos AP. Peripheral giant cell granuloma. Clinicopathologic study of 224 new cases and review of 956 reported cases. Int J Oral Maxillofac Surg. 1988; 17(2):94-9. [PMID: 3133432]

4. Chadwick BL, Crawford PJ, Aldred MJ. Massive giant cell epulis in a child with familial cyclic neutropenia. Br Dent J. 1989; 167(8):279-81. [PMID: 2590585]

5. Tandon PN, Gupta SK, Gupta DS, Jurel SK, Saraswat A. Peripheral giant cell granuloma. Contemp Clin Dent. 2012; 3(Suppl 1):S118-21. [DOI: 10.4103/0976-237X.95121] [PMID: 22629051]

6. Neville BW, Damm DD, Allen CM, Bouquot JE. Soft tissue tumors. In: Neville BW, Damm DD, Allen CM, Bouquot JE, editors. Oral and Maxillofacial Pathology. 3rd ed. Louis: Saunders Publishers. 2009; pp. 507-63.

7. Giansanti JS, Waldron CA. Peripheral giant cell granuloma: review of 720 cases. J Oral Surg. 1969; 27(10):787-91. [PMID: 5258991] 
8. Hirshberg A, Kozlovsky A, Schwartz-Arad D, Mardinger O, Kaplan I. Peripheral giant cell granuloma associated with dental implants. J Periodontol. 2003; 74(9):1381-4. [DOI: 10.1902/jop.2003.74.9.1381] [PMID: 14584874]

9. Dayan D, Buchner A, Spirer S. Bone formation in peripheral giant cell granuloma. J Periodontol. 1990; 61(7):444-6.

[DOI: 10.1902/jop.1990.61.7.444] [PMID: 2117655]

10. Smith BR, Fowler CB, Svane TJ. Primary hyperparathyroidism presenting as a "peripheral" giant cell granuloma. J Oral Maxillofac Surg. 1988; 46(1):65-9. [DOI: 10.1016/0278-2391(88)90303-5] [PMID: 3276854]

11. Burkes EJ, White RP. A peripheral giant-cell granuloma manifestation of primary hyperparathyroidism: report of case. J Am Dent Assoc. 1989; 118(1):62-4. [DOI: 10.14219/jada.archive.1989.0005] [PMID: 2913105]

12. Lim L, Gibbins JR. Immunohistochemical and structural evidence of a modified microvasculature in the giant cell granuloma of the jaws. Oral Surg Oral Med Oral Pathol. 1995; 79(2):190-8. [DOI: 10.1016/S1079-2104(05)80281-1] [PMID: 7614183]

13. Mighell AJ, Robinson PA, Hume WJ. PCNA and Ki-67 immunoreactivity in multinucleated cells of giant cell fibroma and peripheral giant cell granuloma. J Oral Pathol Med. 1996; 25(5):193-9.

[DOI: 10.1111/j.1600-0714.1996.tb01371.x] [PMID: 8835814]

14. Souza PE, Mesquita RA, Gomez RS. Evaluation of p53, PCNA, Ki-67, MDM2 and AgNOR in oral peripheral and central giant cell lesions.
Oral Dis. 2000; 6(1):35-9. [DOI: 10.1111/j.1601-0825.2000.tb00319.x] [PMID: 10673786]

15. Liu B, Yu SF, Li TJ. Multinucleated giant cells in various forms of giant cell containing lesions of the jaws express features of osteoclasts. J Oral Pathol Med. 2003; 32(6):367-75.

[DOI: 10.1034/j.1600-0714.2003.00126.x] [PMID: 12787044]

16. Carvalho YR, Loyola AM, Gomez RS, Araujo VC. Peripheral giant cell granuloma. An immuno-histochemical and ultrastructural study. Oral Dis. 1995; 1(1):20-5. [DOI: 10.1111/j.1601-0825.1995.tb00152.x] [PMID: 7553376]

17. Flanagan AM, Tinkler SMB, Horton MA, Williams MD, Chambers DJ. The multinucleated giant cell granulomas of the jaws are osteoclasts. Cancer. 1988; 62(6):113945. [DOI: 10.1002/1097-0142(19880915)62:6<1139::AIDCNCR2820620617>3.0.CO;2-8] [PMID: 2457425]

18. el-Mofty SK, Osdoby P. Growth behaviour and lineage of isolated and cultured cells derived from giant cell granuloma of the mandible. J Oral Pathol. 1985; 14(7):539-52. [PMID: 3928848]

19. Cohen MA, Grossman ES, Thompson SH. Features of central giant cell granuloma of the jaws xenografted in nude mice. Oral Surg Oral Med Oral Pathol. 1988; 66(2):209-17. [PMID: 3174055]

20. Willing $M$, Engels $C$, Jesse N, Werner $M$, Delling $G$, Kaiser $E$. The nature of giant cell tumor of bone. J Cancer Res Clin Oncol. 2001; 127(8):467-74. [PMID: 11501745]

Received: 25.04.2016 • Accepted: 27.07.2016 


\title{
Periferni gigantocelularni granulom - prikaz bolesnika
}

\author{
Slavoljub Tomić', Bojana Davidović \\ 'Univerzitet u Istočnom Sarajevu, Medicinski fakultet, Katedra za oralnu hirurgiju, Foča, Bosna i Hercegovina; \\ ²Univerzitet u Istočnom Sarajevu, Medicinski fakultet, Katedra za dečju i preventivnu stomatologiju, Foča, Bosna i Hercegovina
}

\begin{abstract}
KRATAK SADRŽAJ
Periferni gigantocelularni granulom (PGCG) ili tzv. epulis gigantocelularis je najčešća oralna lezija porekla džinovskih ćelija. Obično se manifestuje u formi mekotkivnog tumora purpurno crvene ili crveno-lividne boje, koji se sastoji od višejedarnih džinovskih ćelija u monojedarnoj stromi i ekstravazovanih eritrocita. Ova lezija uglavnom ne predstavlja pravu neoplazmu, a po svojoj prirodi može biti reaktivna jer je stimulišu trauma i lokalna iritacija, dok je uzrok najčešće nepoznat.

Ovaj prikaz predstavlja 13-godišnjeg dečaka sa velikom lezijom u frontalnoj regiji gornje vilice, u području očnjaka sa desne strane, koji je zaostao u vilici i pored povoljne vertikalne pozicije i dovoljno raspoloživog prostora za smeštaj u zubni niz. Lezija je u potpunosti ukljonjena u lokalnoj anesteziji, a histopatološki nalaz je bio karakterističan za PGCG. Postoperativni tok je bio bez komplikacija, a početni recidiv nakon četiri meseca je u ponovnom zahvatu kompletno uklonjen, nakon čega više nije bilo recidiva, a zub se spontano spustio i smestio u zubni niz.
\end{abstract}

Ključne reči: periferni gigantocelularni granulom; epulis gigantocellularis

\section{UVOD}

Naziv epulis nastao je je od grčkog epi - na i oulon - desni, a podrazumeva, generalno, svaku izraslinu na desnima bez obzira na njenu etiologiju [1]. Klinički, većina epulisa izgleda slično, te problem predstavlja razlikovanje tih tumoru sličnih masa. Budući da veliki broj promena na gingivi, bar makroskopski, izgleda identično epulisu, u dostupnoj literaturi još uvek nije utvrđena zvanična podela ovakvih lezija.

Najčešće uočena formacija epulisa na desnima, građena od vezivnog tkiva i prekrivena pločastoslojevitim epitelom, jeste epulis gigantocellularis. U literaturi se sreću sinonimi za ovu leziju kao što su: periferni gigantocelularni tumor ili periferni gigantocelularni granulom. Najčešće se javlja u interkaninom sektoru na interdentalnoj papili [2], češće na donjoj vilici sa vestibularne strane [3]. Pet puta je češći od centralnog gigantocelularnog granuloma, koji se razvija u kosti [4].

Periferni gigantocelularni granulom (PGCG) nepoznate je etiologije i sporog rasta [2]. Prema navodima većine autora, uzroci mogu biti stalne iritacije ili traume regije desni na kojima se javlja epulis [5]. Kod nekih pacijenata kojima je dijagnostikovan PGCG izolovan je citomegalovirus [6], pri čemu nije utvrđeno da li je on uzročnik ili samo doprinosi razvoju same bolesti.

U početku, sluzokoža je nepromenjene boje i zadebljala, da bi PGCG vremenom narastao kao impresivna tumefakcija crvene ili tamnocrvene boje i meke konzistencije, koja može da razara koštanu masu [2]. Na površini ove promene mogu se razviti ulceracije. Veličina PGCG obično ne prelazi dimenzije od $5 \mathrm{~cm}$ u prečniku, ali mogu biti i veći. Zbog svoje mase mogu razdvojiti susedne zube [4]. Za njega je karakteristično da mu je baza uža od celokupnog obima tumefekta, kao i da se na njemu mogu uočiti impresije susednih struktura usne šupljine (zubi, obrazi, jezik).

U početku razvoja bolesti na rendgenskom snimku se ne uočava rasvetljenje kosti, ali nakon određenog vremena te promene su i rendgenski vidljive. Tada diferencijalno dijagnostički može podsećati na centralni gigantocelularni granulom.

Terapija je isključivo hirurška i, ako je neophodno, mogu se i ukloniti zubi iz regije granuloma. Recidivi lezije su dosta česti, a najčešće se tumače kao posledica neadekvatnog hirurškog zahvata.
Cilj ovog rada je bio da se predstavi neuobičajena lokalizacija perifernog gigantocelularnog granuloma i ukaže na jednostavno hirurško rešenje kojim je istovremeno omogućeno nicanje neizniklog očnjaka i njegovo smeštanje u zubni niz.

\section{PRIKAZ BOLESNIKA}

Na Kliniku za oralnu hirurgiju Medicinskog fakulteta u Foči roditelji su doveli 13-godišnjeg dečaka sa evidentnim tumefaktom na alveolarnom grebenu gornje vilice u regiji očnjaka sa desne strane. Lezija veličine $3,5 \times 2,5 \mathrm{~cm}$, bubrežastog oblika, crveno-ljubičaste boje bila je lokalizovana od mezijalne strane premolara do polovine prvog gornjeg sekutića (i sa vestibularne i sa palatinalne strane) $\mathrm{i}$ ispunjavala je skoro ceo vestibulum (Slike 1 i 2). Nakon urađenog retroalveolarnog rendgen snimka (Slika 3) uočeno je i prisustvo neizniklog očnjaka u vilici. Urađena je fina aspiraciona biopsija, koja je nakon histopatološkog pregleda potvrdila prisustvo višejedarnih džinovskih ćelija sa hemoragijom u okolini. Vretenaste/upalne ćelije nisu detektovane.

Lezija je u lokalnoj anesteziji u potpunosti uklonjena od okoline u jednom komadu (Slika 4) i poslata na histopatološku analizu. Histopatološki je uočeno prisustvo brojnih višejedarnih ćelija različitog oblika i veličine, koje su sadržavale od 8 do 15 jedara u fibroblastnoj stromi. Uočene su i proširene endotelne ćelije sa ekstravazovanim eritrocitima. Takođe je uočeno i prisustvo nekoliko džinovskih ćelija unutar vaskularnih prostora, kao i znaci osifikacije unutar same strome (Slika 5). Na osnovu uočenih histopatoloških promena evidentno je bilo da se radi o perifernoj gigantocelularnoj leziji. Defekt nastao nakon uklanjanja pakovan je hirurškim zavojem, koji je uklonjen sedam dana posle intervencije.

Nakon četiri meseca pacijent se javio sa recidivom u formi plavo-ljubičastog čvorića veličine pet milimetara (Slika 6), koji je ponovo u lokalnoj anesteziji potpuno uklonjen i pakovan hirurškim zavojem (Slika 7). Očnjak je zauzeo svoje mesto u zubnom nizu. Godinu dana nakon intervencije nije bilo nikakvih znakova eventualnog recidiva, a mekotkivne strukture u okolini zuba u potpunosti su zarasle. 


\section{DISKUSIJA}

Etiologija i priroda PGCG i dalje je nedefinisana. U prošlosti su postojale hipoteze koje su pokušale da objasne prirodu višejedarnih džinovskih ćelija, uključujući i hipoteze da su one ostaci osteoklasta, koji vrše prirodnu resorpciju mlečne denticije ili da su nastale kao reakcija na povrede periosta.

PGCG se može javiti tokom celog života, ali sa najčešćom incidencom u mešovitoj denticiji [4]. Lezije su češće u donjoj vilici $[3,7]$, a u svojoj veličini mogu dosezati i preko dva centimetra u promeru. Klinički je sličan piogenom granulomu, ali se razlikuje uglavnom po plavo-ljubičastoj boji u poređenju sa crvenom bojom tipičnog piogenog granuloma. Nedavno je i objavljen slučaj PGCG povezanog sa dentalnim implantima [8]. Iako se PGCG razvija u mekom tkivu, često se zapaža i lokalna resorpcija kosti alveolarnog grebena. S vremena na vreme teško je oceniti da li je tumorska masa periferna lezija ili je centralni gigantocelularni granulom (CGCG) nastao $u$ koštanom tkivu alveolarnog grebena, koji se širi u meka tkiva gingive $[9,10,11]$.

Histološki, PGCG se sastoji od ostrva višejedarnih džinovskih ćelija u stromi ispunjenoj ovalnim i vretenastim mezenhimal- nim ćelijama i ekstravazovanim eritrocitima. Džinovske ćelije mogu sadržavati nekoliko jedara pa do nekoliko desetina. Neka od njih su velika vezikularna jedra, dok su kod drugih prisutna mala, piknotična jedra. Poreklo džinovskih ćelija je nepoznato. Ultrastrukturne i imunološke studije [12-16] pokazale su da su one, zapravo, nastale od osteoklasta [17]. Većina smatra da one predstavljaju reakcionu komponentu lezije, i da su to mononuklearne ćelije iz koštane srži koje su tu dospele putem krvotoka i njihovom sledstvenom ekstravazacijom, a predstavljaju odgovor na podsticaj iz same strome. Ovaj koncept se zasniva na rezultatima nedavnih studija, korišćenjem kulture ćelija i transplantacijom [18, 19], gde su pronađene džinovske ćelije, kratkog životnog veka, koje nestaju u kulturi, u poređenju sa aktivnom proliferacijom stromalnih ćelija.

Prema nalazima Willing et al. [20] otkriveno je da stromalne ćelije luče citokine i druge faktore diferencijacije ćelija, uključujući monocitni hematotraktantni protein-1 (MCP1), osteoklastični diferencioni faktor (ODF) i makrofag stimulišući faktor (M-CSF). MCP1 je od suštinskog značaja za diferencijaciju osteoklasta i ukazuje da stromalne ćelije stimulišu migraciju monocita u tkivo tumora fuzionišući se u multijedarne džinovske ćelije, nalik osteoklastima. 